\begin{tabular}{ll}
\hline \hline MINING AND METALLURGY INSTITUTE BOR & ISSN: 2334-8836 (Štampano izdanje) \\
UDK: 622 & ISSN: 2406-1395 (Online) \\
\hline \hline
\end{tabular}

Slavica Miletić, Ana Kostov", Dragan Milanović*

\title{
ILLUSTRATION AN ADVANTAGE ASSESSMENT OF THE QUALITY MANAGEMENT SYSTEM IMPLEMENTATION INTO METALLURGICAL ORGANIZATIONS ${ }^{* *}$
}

\begin{abstract}
Implementation of the quality management system (QMS) in organizations is directly linked to the performances and business activity relative to a competition. With increasing market competition and changing markets, the quality system becomes a significant component and is increasingly being researched and identified as a major factor in cooperative advantage over competition, stakeholder satisfaction and maintaining the good customer relationships in almost all organizations connected with metallurgy. This paper implements a multi-criteria approach to a decision-making based on the Analytic Hierarchy Process. The aim of this paper is to illustrate the assessment of benefits of the quality system implementation ranking the criteria for a sustainable development by the MCDM models.

Keywords: Quality System, Analytic Hierarchy Process, advantages
\end{abstract}

\section{INTRODUCTION}

ISO 9001 is an international standard and contains all the requirements where a company can plan and manage by the best way. By implementing the QMS, the organization harmonizes business activity with the international norms and requirements. [1]

This paper is aimed to present an evaluation of implementing benefits into the quality management system in the field of metallurgy, which would encourage managers of the organization to apply it.

Evaluation of the advantages of implementing the ISO 9001-Quality Management System into organizations is important for its positioning, assessment of where it is in relation to a competition, improvement of products and services, dissemination of markets and products, improvement the performance, increasing profits and sustainable development.

This international standard specifies the requirements of the quality management system, as follows:

a. When an organization needs to demonstrate its ability to consistently provide a product or service that meets the requirements of users and applicable laws and regulations;

b. When an organization is aimed to increase a customer satisfaction with the effective system implementation, including the processes of continuous system improvement and demonstrating a compliance with the customer requirements and applicable laws and other regulations, and

\footnotetext{
* Mining and Metallurgy Institute Bor, slavica.miletic@irmbor.co.rs

** The research was funded by the Ministry of Education, Science and Technological Development of the Republic of Serbia as a part of the Project TR 33023: Development of Technologies for Flotation Concentration of Copper Ore and Precious Metals in Order to Achieve the Technological Results
} 


\section{THEORETICAL FRAMEWORK}

c. When all the requirements in this International Standard are generic and intended to be applicable to all organizations in the field of metallurgy, regardless of their type, size and the products they provide.

The purpose of the quality management system (QMS) is to increase the company efficiency through the process approach application [1]. The goal of QMS implementation is for the company to demonstrate the ability of providing the products and services that provide satisfaction to the customer using legislations and regulations. The company that implements the QMS in accordance with the standard requirements is aimed to identify the expectations of users (customer, seller, supplier, employees).

Evaluation of the implementation advantages was done applying the AHP method (Analytical Hierarchical Process), one of the methods of Multiple Criteria Decision Making (MCDM).

The MCDM methods are auxiliary tools for the decision makers, managers in the decision-making process to solve real, diverse problems in various areas of business activities as well as in the field of metallurgy.

In the past decades, several methods have been proposed in the field of MCDM, such as TOPSIS [2], AHP [3], ELECTRE [4], VIKOR [5], COPRAS [6], ARAS [7] and other methods. There are a number of software programs that help the MCDM methods to quickly solve tasks; the most famous are: QM for Windows, Electra, Expert Choice, Decision Lab, Criterium Decision Plus.
The multi-criteria decision-making techniques, MCDM methods, have been used and developed by many researchers and applied in many real problems.

The goal of the researchers is to use the MCDM method to evaluate alternatives or criteria, and find the best solutions to the current problem.

The MCDM methods are multi-criteria decision-making methods that can be defined as the process of selecting the most appropriate solution from a range of available alternatives, based on their performance in relation to a set of evaluation criteria [8].

The choice of MCDM methods is important for the decision makers, but much more important is the proper structuring of the problem itself, which includes the assessment of appropriate alternatives and selection of the most important criteria $[9,10]$.

These methods have their advantages for their application, they consider different criteria in the selection process, namely: financial and non-financial; qualitative and quantitative, and others.

The most common of these models are evaluation methods, Analytical Hierarchical Process (AHP). Thomas Saaty [3] gave the conceptual and mathematical setting of the AHP method.

Methodologically, the AHP is a multicriteria technique that belongs to the class for soft optimization and is based on decomposition a complex real problem in the hierarchy.

The goal of decision maker to be addressed is at the top of the 0-level hierarchy. The criteria that are compared with each other are at the lower level I, while the alternatives that are compared with each criterion are at the level II, Figure 1. 


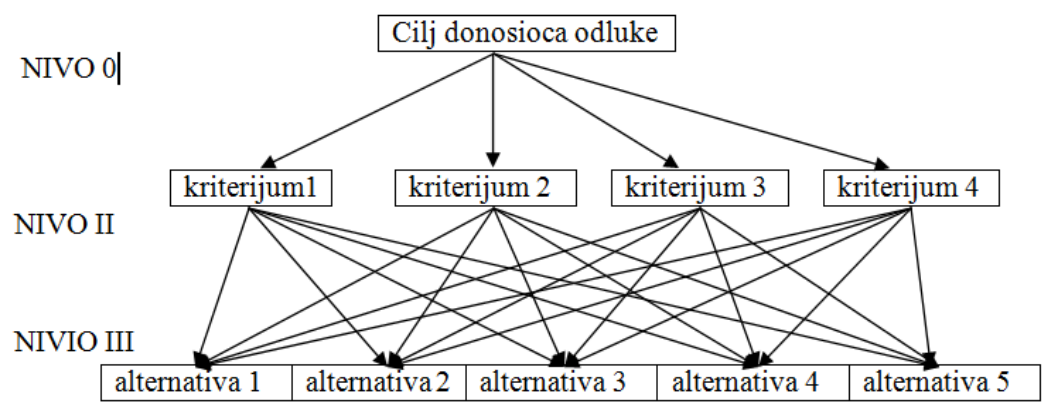

Figure 1 Analytical process of hierarchy

Using the Saaty scale, two elements (cri- $\quad$ teria or alternatives) are compared, Table 1.

Table 1 Saaty scale

\begin{tabular}{|c|l|l|}
\hline Evaluation & \multicolumn{1}{|c|}{ Description } & \multicolumn{1}{c|}{ Explanation } \\
\hline 1 & Same significance & $\begin{array}{l}\text { Two elements are of identical importance in } \\
\text { relation to the goal }\end{array}$ \\
\hline 3 & Weak dominance & $\begin{array}{l}\text { Reasoning slightly favors one element over } \\
\text { another }\end{array}$ \\
\hline 5 & Strong dominance & $\begin{array}{l}\text { Reasoning significantly favors one element } \\
\text { over another }\end{array}$ \\
\hline 7 & Very strong dominance & $\begin{array}{l}\text { Dominance of one element confirmed in prac- } \\
\text { tice }\end{array}$ \\
\hline 9 & Absolute dominance & Dominance of the highest degree \\
\hline $2,4,6,8$ & Intermediate values & Compromise is needed \\
\hline
\end{tabular}

So first, the criteria are compared with each other in relation to the goal of decision at the top.

Then, each criterion is compared with each alternative in relation to the goal of the decision maker (assessment of significance); the order of alternatives by importance (ranking) is determined.

The synthesis of all evaluations is performed according to a mathematical model where the weight coefficients of all elements of the hierarchy are determined. The sum of the weight coefficients of elements is equal to 1 , which enables the decision maker to evaluate or rank all elements in the horizontal and vertical sense $[11,12]$.
The AHP is one of the methods where the inconsistencies of decision makers in the process of reasoning and evaluation of elements of hierarchy are identified and analyzed.

The degree of consistency (CR) represents the ratio of consistency index (CI) and random index (RI):

$$
\mathrm{CR}=\frac{C I}{R I} \lambda
$$

where the CI consistency index is calculated from the form:

$$
\mathrm{CI}=\frac{\lambda_{\max }-n}{n-1}
$$


where $\lambda_{\max }$ is the maximum eigenvalue of the comparison matrix and the rule is that the closer $\lambda_{\max }$ is to the number $\mathrm{n}$, the less inconsistency will be.
The random index (RI) depends on the order of matrix, and is taken from Table 2, in which the first row represents the order of comparison matrix, and the second the random indexes [3].

Table 2 Random indexes [3]

\begin{tabular}{|c|c|c|c|c|c|c|c|c|c|c|c|c|c|c|}
\hline 1 & 2 & 3 & 4 & 5 & 6 & 7 & 8 & 9 & 10 & 11 & 12 & 13 & 14 & 15 \\
\hline 0.0 & 0.0 & 0.58 & 0.9 & 1.12 & 1.24 & 1.32 & 1.41 & 1.45 & 1.49 & 1.51 & 1.48 & 1.56 & 1.57 & 1.59 \\
\hline
\end{tabular}

The consistency degree (CR) is less than 0.10 and then the result is correct, there is no need for re-analysis. If the $\mathrm{CR}$ is greater than 0.1 , then a re-analysis of inconsistency is required until the consistency degree less than 0.1 is obtained.

\section{NUMERICAL ILLUSTRATION}

The idea of the author is to illustrate the AHP method application for assessment the importance of the advantage criteria of implementation the quality management systems in the field of metallurgy. The AHP method is used as an auxiliary tool for the decision makers (DO) to solve the real semistructural and non-structural decision problems using the Criterium Decision Plus software.

The goal is defined by the decision maker. By evaluation the importance of criteria, the advantages of implementing the quality management system are further defined by the criteria.

The criteria contain the most important characteristics for assessing the benefits of implementing a quality management system.

The evaluation criteria are defined as the evaluation criteria that are of great importance for decision makers to resolve the real conflict problems and making a final decision.

There are the following rules in defining the criteria:

1. The criteria are closely related to the objective;
2. They relate in a great detail and precision to the quality structure of decision;

3. They are simply formulated and understood;

4. They are operationalized in relation to the level of achievement; and

5. They are known to the decision makers.

The selected criteria for evaluation the benefits of implementation the quality management system are as follows:

1. Increasing the customer satisfaction;

2. Increasing the employee safety;

3. Market penetration and product diversification;

4. Participation and tendering;

5. Measuring the company performances;

6. Company image; and

7. Company development and improvement of products and services.

Criterion 1. Criterion of increasing the customer satisfaction is important for the survival of an organization. Quality service and product of the organization means that the customer is satisfied with the choice of products and services. By increasing the customer satisfaction, the organization takes a better position in relation to the competition, becomes more competitive, reduces the servicing costs, reduces the complaints and 
reclamations, increases the production and sale of products, and thus increases the profits. Dissatisfied users of products and services are a threat to the organization.

Criterion 2. Increasing employee safety. The implementation of the QMS increases the safety of employees and enables employees to use the ISO standards with which they perform work tasks more efficiently. Standardized QMS procedures help employees to improve the way they do the business activities, give them instructions for work, provide models for creating better quality products and services with constant control of the work process. The advantage of this criterion is reflected in the establishment of a better organizational culture.

Criterion 3. Market penetration and product diversification: By implementation the quality management system, organizations receive the certificates on introduction the ISO 9001 standard. Organizations make their own advertisements and websites. Advertisements and websites provide organizations with market expansion increasing the sales of current products (market penetration) and expanding the range of products and services (product diversification).

Criterion 4. Participation and tendering. This criterion is important for organizations and one of the conditions for cooperation with organizations that have already implemented the ISO standards. Possession of a certificate is a condition for participation and winning a tender; it is also a condition for organization to be able to work. Implementation of the QMS is a safe business for organizations and constant improvement and management the quality system of working processes.
Criterion 5. Image of the organization. This criterion is important for the present and future of an organization. With the QMS introduction, the organizations gain a well-positioned place in the market. The metallurgical organization enters the business world with a recognized certification that deals with the constant improvement of the quality of products and services. This criterion is reflected in improvement the image of organization, improvement the organizational culture, striving to the quality products and services, continuous improvement the production processes, work processes, harmonization of products and services with the customer requirements and constant checks.

Criterion 6. Measuring the organization performances. This criterion is important for the organization business activity. With the QMS introduction, the performance of an organization is constantly checked on the basis of eight principles of the quality management system. Verification is performed by the senior management in order to meet the needs of all stakeholders.

Criterion 7. Development of the organization and improvement the products and services, introduction of the ISO 9001 standard, quality management systems, increases the customer satisfaction with the effective system application. This criterion includes the constant improvements in the work process of organizations and proving a compliance with the requirements of all users.

The criteria defined in this way are compared with each other in relation to the goal using the Saaty scale shown in Table 1. Values of the mutual comparison of criteria are entered in Table 3 . 
Table 3 Matrix of criteria comparison

\begin{tabular}{|c|c|c|c|c|c|c|c|}
\hline Criteria & $\begin{array}{c}\mathrm{C}_{1} \\
\text { (Increasing } \\
\text { of customer } \\
\text { satisfaction) }\end{array}$ & $\begin{array}{c}\mathrm{C}_{2} \\
\text { (Increasing } \\
\text { of employee } \\
\text { safety) }\end{array}$ & $\begin{array}{c}\mathrm{C}_{3} \\
\text { (Market penetra- } \\
\text { tion and product } \\
\text { diversification) }\end{array}$ & $\begin{array}{c}\mathrm{C}_{4} \\
\text { (Participa- } \\
\text { tion and } \\
\text { tendering) }\end{array}$ & $\begin{array}{c}\mathrm{C}_{5} \\
\text { (Company } \\
\text { image) }\end{array}$ & $\begin{array}{c}\mathrm{C}_{6} \\
\text { (Measuring an } \\
\text { organization } \\
\text { performances) }\end{array}$ & $\begin{array}{c}\mathrm{C}_{7} \\
\text { (Company } \\
\text { development and } \\
\text { improvement of } \\
\text { products and } \\
\text { services) } \\
\end{array}$ \\
\hline $\mathrm{C}_{1}$ & 1 & 5 & 3 & 7 & 5 & 7 & 5 \\
\hline $\mathrm{C}_{2}$ & & 1 & $1 / 2$ & $1 / 3$ & $1 / 3$ & 1 & $1 / 2$ \\
\hline $\mathrm{C}_{3}$ & & & 1 & 1 & $1 / 3$ & 5 & 3 \\
\hline $\mathrm{C}_{4}$ & & & & 1 & $1 / 2$ & $1 / 5$ & $1 / 3$ \\
\hline $\mathrm{C}_{5}$ & & & & & 1 & 1 & $1 / 2$ \\
\hline $\mathrm{C}_{6}$ & & & & & & 1 & $1 / 3$ \\
\hline $\mathrm{C}_{7}$ & & & & & & & 1 \\
\hline
\end{tabular}

This paper requires 7 comparisons. The number of comparisons is equal to $\mathrm{n} x$ ( $\mathrm{n}$ $1) / 2$. So it should correspond to the number of combinations of $n$ elements of the second class, but without repetition. The value 1 is written everywhere on the main diagonal.

Criterium Decision Plus software was used to determine the weighting coeffi- cients for easier mathematical calculation and more precise evaluation of the criteria.

Table 4 shows the results obtained by the AHP calculation. The consistency degree according to the calculation should be less than 0.1 , which is also obtained here; its value is 0.053 .

Table 4 Results obtained by the AHP calculation

\begin{tabular}{c|c|c|c|c|c|c|c} 
Criteria & $\mathbf{C}_{\mathbf{1}}$ & $\mathbf{C}_{\mathbf{2}}$ & $\mathbf{C}_{\mathbf{3}}$ & $\mathbf{C}_{\mathbf{4}}$ & $\mathbf{C}_{\mathbf{5}}$ & $\mathbf{C}_{\mathbf{6}}$ & $\mathbf{C}_{\mathbf{7}}$ \\
\hline $\begin{array}{l}\text { Weighting coefficients of } \\
\text { criteria }\end{array}$ & 0.393 & 0.068 & 0.146 & 0.068 & 0.128 & 0.085 & 0.113 \\
\hline
\end{tabular}

Consistency coefficient $0.053<0.1$

The following results were obtained by the data processing.

Criterion $\boldsymbol{C}_{3}$, market penetration and product diversification are at the second place in importance for the needs of introduction the quality management system, because its weighting coefficient is 0.146 . The implementation of QMS enables the organization to expand the market and increase production while constantly monitoring the quality of products and services. The expansion of the market and increased sales of products and services of the metallurgical organization are beco- ming more profitable. The advantages of this criterion bring the organization to a better position.

Criterion $\boldsymbol{C}_{5}$, the image of metallurgical organization is at the third place in importance for the needs of QMS implementation, because its weighting coefficient is 0.128 . The advantages of this criterion for decision makers are: the ability of metallurgical organization to improve the organizational culture in the future, to improve the quality of products and services with constant checking of work processes and constant striving to improve the image. 
Criterion $\boldsymbol{C}_{7}$, development of metallurgical organization and improvement the products and services are at the fourth place, because its weighting coefficient is 0.113 . The advantages of this criterion for the QMS introduction are: increased satisfaction of all stakeholders including the constant checks of employees, suppliers, users, customers by the internal and external auditors. One significant advantage of this criterion is the verification of the use of QMS standards and compliance with the user requirements.

Criterion $\boldsymbol{C}_{6}$, measuring the performance of metallurgical organization ranks the fifth place in advantage for the QMS implementation, because its weighting factor is 0.085 . The advantages of introduction the QMS are: constant checking of the organization performance based on the eight principles of the quality management system performed by the senior management in order to meet the needs of all stakeholders (employees, users, distributors, suppliers, and others).
Criterion $\boldsymbol{C}_{2}$, increasing the employee safety and criterion $C_{4}$, participation and tendering, rank the sixth place in the assessment of benefits of the QMS introduction, because their weighting coefficients are 0.068 . These two criteria are equally important for decision makers when deciding to introduce the ISO standards.

The advantages of evaluating the QMS introduction of these criteria are: procedures that employees must follow when performing their work duties and applying and obtaining the tenders. Without procedures, the metallurgical organizations cannot do business activities with other organizations that have implemented the QMS, there is no participation and tendering. Not following the procedures prescribed by the QMS, many work processes cannot be accredited, while the scientific research institutions (institutes and faculties) cannot be accredited for work.

Table 5, illustration of criteria, shows the order of criteria advantages as an aid to decision makers in deciding on introduction the quality management system.

Table 5 Illustration of criteria

\begin{tabular}{clc} 
Ord. No. & \multicolumn{1}{c}{ Criteria } & Result \\
\hline 1. & $\mathrm{C}_{1}$ (Increasing of customer satisfaction) & 0.393 \\
\hline 2. & $\mathrm{C}_{3}$ (Market penetration and product diversification) & 0.146 \\
\hline 3. & $\mathrm{C}_{5}$ (Image of metallurgical organization) & 0.128 \\
\hline 4. & $\begin{array}{c}\mathrm{C}_{7} \text { (Development of metallurgical organization and } \\
\text { improvement the products and services) }\end{array}$ & 0.113 \\
\hline 5. & $\mathrm{C}_{6}$ (Measuring of metallurgical organization performances) & 0.085 \\
\hline 6. & $\mathrm{C}_{2}, \mathrm{C}_{4}$ (Increasing the employee safety; participation & 0.068
\end{tabular}

Figure 2 shows the decision hierarchy obtained using the Criterium Decision Plus software, while Figure 3 shows a diagram illustrating the criteria advantages. 


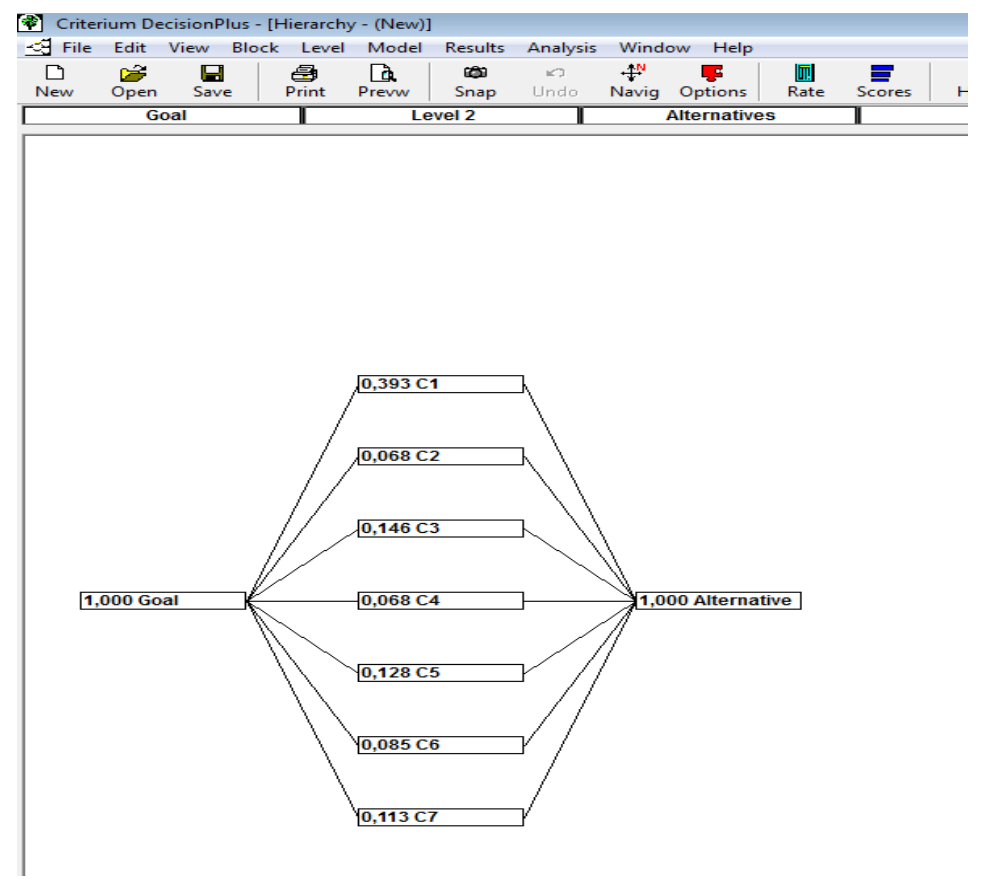

Figure 2 Hierarchy of decision making

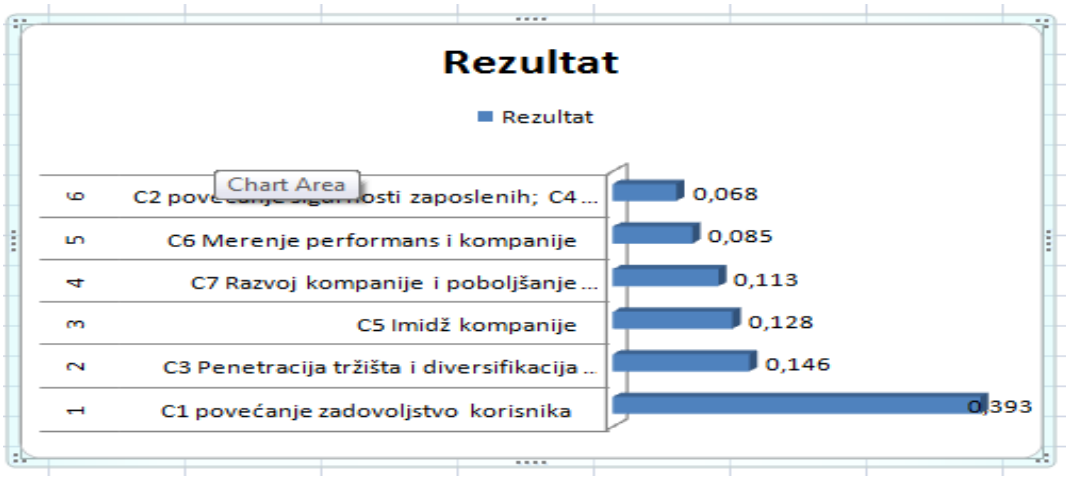

Figure 3 Diagram of graphical representation the illustration of advantages of implementing the quality management system

\section{CONCLUSION}

Based on the realized research, it was concluded that the assessment of advantages of implementation the quality management system gives a clear picture to the decision makers in the metallurgical organizations about the criteria. 
Illustration of criterion evaluation was done by the AHP method using the Criterium Decision Plus software and the following results were obtained:

- Numerical illustration shows that the biggest advantage for the QMS introduction has the criterion $\mathrm{C}_{1}$, user satisfaction whose weighting factor is 0.393 .

- Then, criterion $\mathrm{C}_{3}$, market penetration and product diversification, with a weighting factor of 0.146 .

- Criterion $\mathrm{C}_{5}$, the image of the metallurgical organization, with a weighting factor of 0.128 . Criteria $\mathrm{C}_{3}$ and $\mathrm{C}_{5}$ have approximate values so that their impact on decision makers acts almost equally.

- Criterion $\mathrm{C}_{6}$, measuring the performance of metallurgical organization, with a weighting factor of 0.085 and criterion $\mathrm{C}_{2}$, increasing the employee safety and criterion $\mathrm{C}_{4}$, participation and tendering, with a weighting factor of 0.068 act identically on decision makers when deciding to implement the quality management system.

Methods of multi-criteria decision-making have application in the decision-making process in various economic branches, including in the field of metallurgy.

This methodology in science is subject to a constant improvement and upgrading in various scientific branches that are based on several diverse criteria and alternatives.

\section{REFERENCES}

[1] Miletić S., Bogdanović D., Paunković Dž., (2015). Selection the Optimal Model of Integrated Sustainable Management System in the Mining Companies. Journal Mining and Metallurgy Engineering Bor, Vol. 2, 181-204.
[2] Hwang, C.L., Yoon, K. (1981). Multiple Attribute Decision Making Methods and Applications. Springer, New York.

[3] Saaty, T.L. (1980). The Analytical Hierarchy Process: Planning, Priority Setting, Resource Allocation. McGraw-Hill, New York.

[4] Roy, B. (1991). The Outranking Approach and the Foundation of ELECTRE Methods. Theory and Decision, 31(1), 49-73.

[5] Opricovic, S. (1998). Multicriteria Optimization of Civil Engineering Systems. Faculty of Civil Engineering, Belgrade (in Serbian).

[6] Zavadskas, E.K., Kaklauskas, A., Sarka, V. (1994). The New Method of Multicriteria Complex Proportional Assessment of Projects. Technological and Economic Development of Economy, 1(3), 131-139.

[7] Zavadskas, E.K., Turskis, Z. (2010). A New Additive Ratio Assessment (ARAS) Method in Multicriteria Decision Making. Technological and Economic Development of Economy, 16(2), 159-172.

[8] Stanujkić, D., Zavadskas, E. K., Ghorabaee, M. K., Turskis, Z. (2017). An Extension of the EDAS Method Based on the Use of Interval Grey Numbers. Studies in Informatics and Control, 26(1), 5-12.

[9] Bufardi, A., Gheorghe, D., Hirouchakis, P., (2004). Multicriteria Decision-Aid Approach for Product End-of-Life Alternative Selection. International Journal of Production Research, 42(16), 3139-3157.

[10] Mergias, I., Moustakas, K., Papadopolos, M., Loiyidou, M., (2007). Multi-Criteria Decision Aid Approach 
Fort the Selection of the Best Compromise Management Scheme for ELVs: The case of Cyprus. Journal of Hazardous Materials, 147, 706-717.

[11] Saaty, T. L., Tran, L. T. (2007). On the Invalidity of Fuzzifying Numerical Judgments in the Analytic Hierarchy
Process. Mathematical \& Computer Modelling, 46(7/8), 962-975.

[12] Saaty, T. L., Peniwati, K., Shang, J. S. (2007). The Analytic Hierarchy Process and Human Resource Allocation: Half the story. Mathe-matical \& Computer Modelling, 46(7/8), 10411053. 